Document downloaded from:

http://hdl.handle.net/10251/104254

This paper must be cited as:

Doménech Antich, EM.; Martorell Alsina, SS. (2017). Assessment of safety margins of exposure to non-genotoxic chemical substances in food. Food Control. 79:1-9. doi:10.1016/j.foodcont.2017.03.018

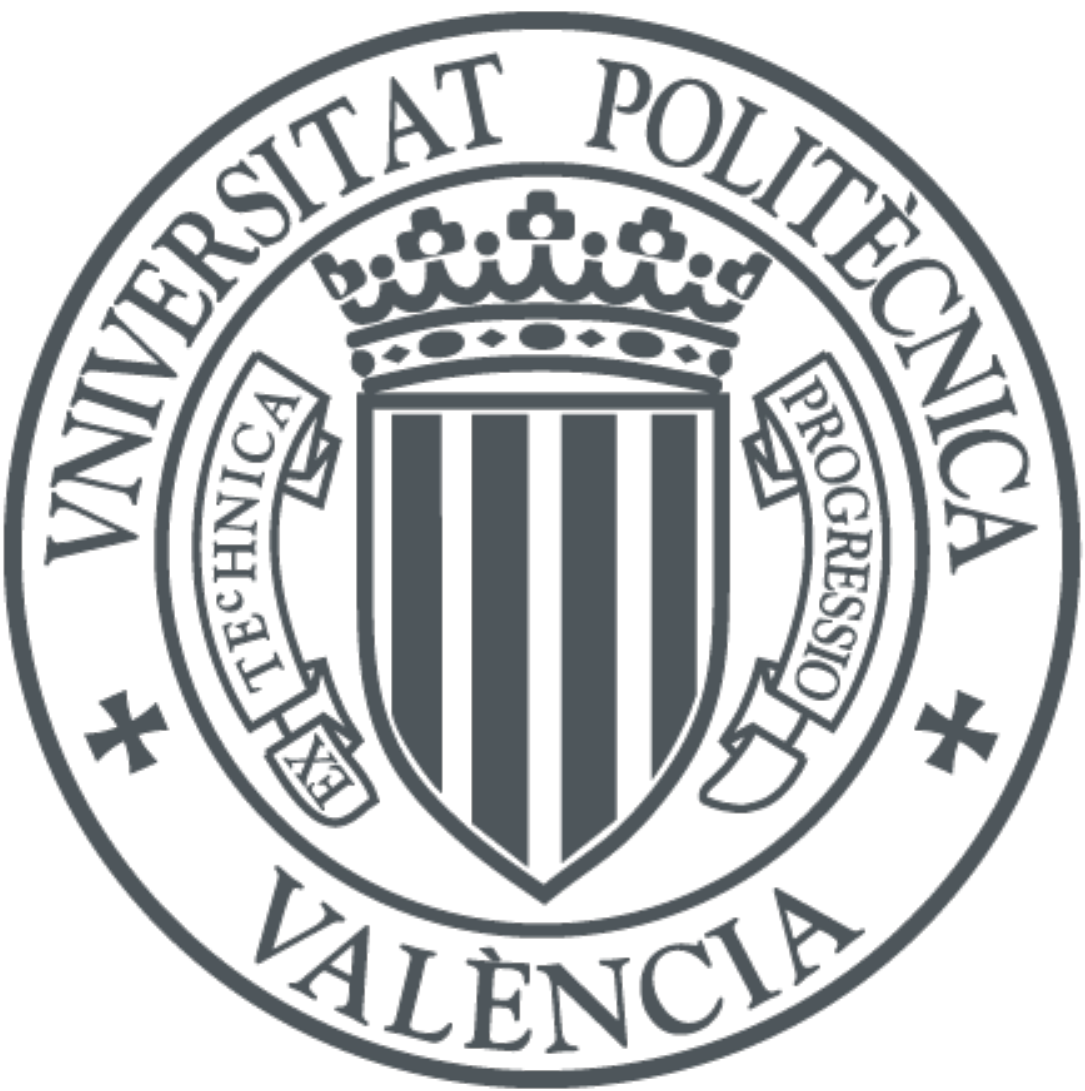

The final publication is available at

http://doi.org/10.1016/j.foodcont.2017.03.018

Copyright Elsevier

Additional Information 


\title{
Assessment of safety margins of exposure to non-genotoxic chemical substances in food
}

\author{
Eva Doménech ${ }^{\text {a*}}$, \\ a Institute of Food Engineering for Development (IUIAD), Department of Food Technology (DTA), \\ Universitat Politècnica de València, Camino de Vera, 16, 46022 Valencia, Spain \\ * Corresponding author: evdoan@tal.upv.es
}

\section{Sebastian Martorell ${ }^{b}$}

bMEDASEGI research group. Department of Chemical and Nuclear Engineering, Universitat Politècnica de València, Camino de Vera, 16, 46022 Valencia, Spain

\begin{abstract}
The concept of Food Safety Margin (FSM) was introduced in microbiological risk analysis as an alternative approach to risk characterization within the informed-risk decision-making process. Its aim was to verify compliance with food safety objectives by assessing the effects of uncertainties. This paper describes the fundamentals and develop a new formulation of safety margins to verify compliance with food safety goals in relation to exposure to non-genotoxic chemical hazards. Both classical and probabilistic metrics were used to compare a given exposure to an estimated daily intake (EDI) with a given safety goal, the acceptable daily intake (ADI). The safety margins of these metrics were assessed in the exposure of peaches to organophosphorus pesticides. The pesticides considered were Azinphos-methyl, Chlorpyrifos, Diazinon, Dimethoate, Methamidophos, Parathion-methyl and Phosmet. The concentrations were obtained from the USDA pesticide database. The study period included the 11 years in which peaches were analysed from 1994 to 2014. The results show the importance of using the effect of uncertainty instead of mean values for risk characterization and that not only safety margins increased during this period but also that uncertainty was reduced. In general, large safety margins were observed in the period studied and few situations were found in which exposure was outside the safety limits.
\end{abstract}




\section{Introduction}

The consumption of potentially harmful contaminants remains a real problem that can cause human illness and significant economic losses in both developed and non-developed countries. Both chemical and biological contaminants are the most frequent hazards in food. In fact, the 2014 report on the management of food alerts in Spain showed that chemical hazards were detected in $54.63 \%$ of the notifications, while biological hazards were identified in $28.35 \%$ (AECOSAN, 2014).

Humans are exposed to a wide variety of chemical hazards throughout their lives via environmental pollution of the air, water, soil and food. Chemical substances play an important role in food as they can be intentionally added as additives to prolong shelf-life or as flavouring to make food tastier. Although chemicals such as pesticides are not intentionally added, they are sometimes present in the final product. For example, the EFSA's report on pesticide residues in food (2013) shows that the concentration of pesticides in $97.4 \%$ of samples originating in the EU fell within the legal limits, i.e. the MRL (Maximum Residue Level); 54.6\% were free of detectable residues, while $1.5 \%$ of the samples clearly exceeded it (EFSA, 2015). Similar results were published by the USDA pesticide data programme, in which over $41 \%$ of the samples tested had no detectable pesticide residue (USDA, 2016a). Of the cases detected (59\%), more than $99 \%$ had residues below the tolerances established by the MRL. The data also indicated the disquieting presence of multiple pesticides, in fact, the samples tested during 2014 showed that only $14.8 \%$ contained 1 pesticide, and the remaining $43.7 \%$ contained more than 1 pesticide, while $12.7 \%$ had two, $1 \%$ had nine and in an extreme case, $0.01 \%$ of the samples had 17 different pesticides. (USDA, 2016a). High concentrations of pesticides in food beyond the MRL can jeopardize consumer health if they are higher than the safety limit, i.e. the ADI (Admissible Daily Intake) in the nongenotoxic chemical hazard framework.

In order to preserve consumer safety, in recent decades risk assessment, risk management and risk communication have been formalised and incorporated into a process known as risk analysis. This has been gradually introduced as a tool to support decision-making processes in food management policies aimed at improving food safety in the global framework, where food safety principles must follow ALARA criteria (Domenech \& Martorell, 2016). This new focus has enabled a change from a hazard-based approach to a risk-based approach (FAO/WHO 2005; CAC, 2007).

Risk assessment provides a systematic means of assessing, both qualitatively and quantitatively, the probability of the occurrence and the severity of known or potentially adverse health effects in a given population, based on hazard identification, hazard characterization, exposure assessment and risk characterization. The results obtained through risk assessment are the foundations of risk management policies, whose aim is to weigh policy alternatives and propose appropriate prevention and control options (CAC, 2007).

In the context of quantitative microbiological risk assessment, the food safety margin (FSM) was 
introduced as a new risk characterization metric to verify compliance with food safety objectives (FSO), addressing the effect of uncertainties. In this way, FSM is able to support microbiological risk management in the risk-informed decision-making framework (Doménech \& Martorell, 2016). Its classical approach is intended to be used to measure the Euclidean distance between exposure, FSO, and a safety threshold, which has to be preserved in order to guarantee an appropriate level of protection (ALOP). Alternatively, the probabilistic approach permits estimation of the probability that exposure does not violate the corresponding safety limit, or, complementarily, estimates the exceedance probability and its uncertainty. This approach fits the realistic formulation of the condition for verification of the safety threshold, particularly for microbiological hazards, in compliance with the FSO. Having a quantitative measure of FSM permit us to assess whether the margin between exposure and the safety threshold is big enough and to estimate the increase or decrease of the margin after changes in food chain conditions, i.e. comparing the safety margin before and after the change.

The objective of this paper is thus to describe the fundamentals and to develop a new formulation to measure the margin between exposure to nongenotoxic chemical hazards, or Estimated Daily Intake (EDI) and the safety limit or Admissible Daily Intake (ADI). Both classical and probabilistic metrics are proposed to provide verification of the compliance of food safety goals in relation to exposure to non-genotoxic chemical hazards and assess the effects of random uncertainties. In a case study, these metrics were applied to measure the safety margins of exposure to organophosphorus pesticides in peaches.

\section{Risk assessment of non-genotoxic chemicals, addressing uncertainty}

Risk assessment of chemical hazards in food, e.g. non-genotoxic chemicals, can generally be described as characterizing the potential hazards and the associated risks to life and health resulting from the exposure of humans to chemicals present in food over a specified period (FAO/WHO, 2009). This assessment consists of four steps: hazard identification, hazard characterization, exposure assessment and risk characterization.

Risk assessment must include the appropriate uncertainty characterization and treatment (IPCS, 2008, CAC, 2013; Dorne\& Fink-Gremmels, 2013; WHO, 2014). Uncertainty can be categorized as either "random" or "epistemic" (Domenech \& Martorell, 2016). The former reflects our inability to predict random observable events and represents the true heterogeneity of the population, which is a consequence of both biological and physical systems and is irreducible by further measurements, so that it is often referred to as "variability". Epistemic uncertainty represents our lack of knowledge, which is often divided into three main categories: completeness, model and parameter uncertainty (Martorell et al., 2014). Random uncertainty is the only type of uncertainty considered in this paper.

According to (Martorell et al., 2014), the treatment of uncertainties in risk assessment depends on the type of 
uncertainty. Uncertainty assessment is a type of treatment for random uncertainty, which is often based on a probabilistic approach to uncertainty formulation and propagation by a standard Monte Carlo method.

\subsection{Hazard identification}

This stage consists of identifying possible chemical hazards and taking into account the possibility of adverse health effects. With this aim the available data on toxicity, analyses and observations in humans or domestic animals are considered to decide whether a chemical should be considered a hazard.

\subsection{Hazard characterization}

Hazard characterization describes the relationship between the administered dose of a chemical and the adverse health effect that it produces (FAO/WHO, 2009). These effects can range from mild eye irritation and nausea to serious chronic diseases, such as cancer. The description of the dose-response, which quantifies the relationship between the amount of exposure to a chemical and the extent of toxic injury or disease, is different for non-genotoxic and genotoxic carcinogens. Those acting via genetic alteration are called genotoxic carcinogens and contrast with nongenotoxic carcinogens, which do not damage DNA but act as tumour promoters. Non-genotoxic carcinogens usually affect only one organ and because of the nature of their indirect action mechanism have an action threshold (Leeuwen \& Vermeire, 2007). The exact action mechanism of nongenotoxic carcinogens has as yet only been partially elucidated, but the end result is usually increased proliferation in specific tissues caused by excessive secretion of hormones, or by injury, or can be receptor-mediated (e.g. peroxisome proliferation).

Considering pesticides as a type of non-genotoxic chemical hazard, the ADI represents the threshold value, which is a reference limit for risk characterization in relation to food safety goals. The ADI is the amount of a chemical to which a person can be exposed daily for a long period without suffering harmful effects (WHO, 2004). It is determined by applying safety factors such as uncertainty data to the highest dose in human or animal studies, which has been shown not to cause toxicity. The WHO (2014) provides guidance on evaluating and expressing uncertainty in hazard characterization and establishes an ADI that guarantees the appropriate level of protection for humans.

\subsection{Exposure assessment}

Exposure assessment is defined as the qualitative or quantitative evaluation of the likely intake of chemical agents via food, as well as exposure from other sources if relevant (FAO/WHO 2006). More recently, the EFSA (2011) defined the same concept as a combination of the data on concentrations, i.e. level and frequency of a chemical substance present in food and on the quantity of those foods consumed. Exposure assessment must include uncertainty assessment. The ICPS (2008) provides guidance on uncertainty treatment in chemical exposure assessment. 
2.3.1. Formulation of estimated daily intake

The EDI is often used for assessment of exposure to chemical hazards, which is formulated for a particular chemical hazard $i$ as follows:

EDI $\left(\mathrm{H}_{i}\right)=\frac{\mathrm{H}_{i} * \mathrm{C}}{\mathrm{Bw}}$

where $H_{i}\left(\mathrm{mg} \mathrm{kg}^{-1}\right)$ is the concentration of a chemical hazard, $i$; $C\left(\mathrm{~kg}\right.$ person ${ }^{-1} \mathrm{~d}^{-}$ $\left.{ }^{1}\right)$ represents the daily consumption of the food and $B w\left(\mathrm{~kg} \mathrm{person}^{-1}\right)$ refers to body weight.

\subsubsection{Assessment of EDI including uncertainty assessment}

Mean values are often used for $H_{i}, C$, and $B w$ in order to estimate a mean value for the $\operatorname{EDI}\left(\mathrm{H}_{\mathrm{i}}\right)$ using Eq. (1). By so doing, the uncertainty of input data is not taken into account. However, in $\operatorname{EDI}\left(\mathrm{H}_{\mathrm{i}}\right)$ assessment, uncertainty arises from insufficient knowledge about relevant exposure scenarios and data (IPCS 2008). The variability of input data is a type of random uncertainty inherent to the distribution of food consumption, distribution of chemical concentrations, physical differences between groups of people exposed, etc. (Domenech et al., 2007; WHO, 2014). In this paper, the data uncertainty was the only one considered.

Assessment of $\operatorname{EDI}\left(\mathrm{H}_{\mathrm{i}}\right)$ by Eq. (1) must therefore include uncertainty assessment of the random uncertainty, which is often based on a probabilistic approach for formulation and propagation by the standard Monte Carlo method (Martorell et al., 2014). First, all the input parameters, i.e. $H_{i}, C$, and $B w$, are associated with a type of probability density function $(p d f)$ to account for their inherent variability, e.g. exponential, lognormal, or gamma-poison, etc. pdf. The uncertainty propagation is then developed, for example by using a standard Monte Carlo method to propagate variability from input parameters to the output EDI $\left(\mathrm{H}_{\mathrm{i}}\right)$ using Eq. (1). This yields a $p d f$ for the $\operatorname{EDI}\left(\mathrm{H}_{\mathrm{i}}\right)$.

\subsubsection{Relationship between EDI and ADI}

Fig. 1 shows the relationship between the concepts of $\mathrm{EDI}\left(\mathrm{H}_{\mathrm{i}}\right)$ and ADI for a given non-genotoxic chemical hazard, $i$. Two $p d f$ of EDI are represented, i.e. $\mathrm{EDI}_{1}\left(\mathrm{H}_{\mathrm{i}}\right)$ (green line) and $\mathrm{EDI}_{2}\left(\mathrm{H}_{\mathrm{i}}\right)$ (blue line). In addition, the mean point and the $95^{\text {th }}$ percentile are shown for both of these, $\operatorname{EDI}_{1}\left(\mathrm{H}_{\mathrm{i}}\right)_{\mathrm{m}}$ and $\mathrm{EDI}_{1}\left(\mathrm{H}_{\mathrm{i}}\right)_{95 \text { th }}$ for Distribution 1, and $\mathrm{EDI}_{2}\left(\mathrm{H}_{\mathrm{i}}\right)_{\mathrm{m}}$ and $\mathrm{EDI}_{2}\left(\mathrm{H}_{\mathrm{i}}\right)_{95}$ th for Distribution 2. On the other hand, the ADI for the hazard, $i$, considered as the safety threshold, is represented by a vertical grey line. The mean value of both EDI is the same. However, $\mathrm{EDI}_{2}\left(\mathrm{H}_{\mathrm{i}}\right)$ shows a proportion of unsatisfactory results, i.e. a fraction of exposure to the non-genotoxic chemical hazard exceeding the ADI, or the socalled exceedance probability, which may be associated with different risk management practices. The relationship between the $\mathrm{EDI}\left(\mathrm{H}_{\mathrm{i}}\right)$ and the ADI is used in the following sections.

\subsection{Risk characterization}

Risk characterization is the final step in risk assessment and is defined as the qualitative and/or quantitative estimation, including attendant uncertainties, of the exposure assessment 
and the severity of known or potential adverse health effects in a given population (Dorne \& Fink-Gremmels, 2013). In order to reach this aim, two new concepts were introduced: the HQ (hazard quotient) and HI (Hazard index) (EPA, 1986; EFSA 2014).

\subsubsection{Formulation of HQ and HI}

HQ is a metric of the risk of individual chemical hazards and is often used for substances with a threshold. HQ is formulated by Eq. (2):

$H Q\left(H_{i}\right)=\frac{\operatorname{EDI}\left(H_{i}\right)}{\operatorname{ADI}_{i}}$

where for a chemical hazard, $i, \operatorname{EDI}\left(\mathrm{H}_{\mathrm{i}}\right)$ is the estimated daily intake and $\mathrm{ADI}_{\mathrm{i}}$ is the acceptable daily intake $\left(\mu \mathrm{g} \mathrm{kg}^{-1} \mathrm{~d}^{-1}\right)$.

It is now generally accepted that risk assessment of individual chemicals is not enough and mixed risk assessment (MRA) is needed. This new approach focuses on assessing the cumulative risk to human health or the environment from multiple chemicals via multiple routes (Boobis et al., 2008; Kortenkamp et al., 2009; Evans et al., 2015). With this in mind, the HI (hazard index) of the average daily individual food consumption is formulated as the sum of the $\mathrm{HQ}\left(\mathrm{H}_{i}\right)$ calculated for each chemical hazard, i, Eq. (3).

$H I=\sum_{i=1}^{n} H Q\left(H_{i}\right)$

2.4.2. Assessment of HQ and HI including uncertainty assessment

Assessment of $\mathrm{HQ}\left(\mathrm{H}_{\mathrm{i}}\right)$ and $\mathrm{HI}$ using Eqs. (2) and (3), respectively, must include uncertainty assessment in a similar way as when assessing $\operatorname{EDI}\left(\mathrm{H}_{\mathrm{i}}\right)$. Since it is assumed here that $\mathrm{ADI}$ i takes a constant value for each non-genotoxic chemical hazard, $i$ is assessed considering only the variability of $\operatorname{EDI}\left(\mathrm{H}_{\mathrm{i}}\right)$. Again, a standard Monte Carlo method is used to propagate variability from the input $\operatorname{EDI}\left(\mathrm{H}_{\mathrm{i}}\right)$ to the outputs $\mathrm{HQ}\left(\mathrm{H}_{\mathrm{i}}\right)$ and $\mathrm{HI}$, using Eqs. (2) and (3). This yields a $p d f$ for each $\mathrm{HQ}\left(\mathrm{H}_{\mathrm{i}}\right)$ and the $\mathrm{HI}$.

Mean values are often adopted for $\mathrm{EDI}\left(\mathrm{H}_{\mathrm{i}}\right), \mathrm{HQ}\left(\mathrm{H}_{\mathrm{i}}\right)$ and HI. Thus, conventionally, a mean value of $\mathrm{HI}$ less than 1 would indicate that on average the total exposure does not exceed the level considered to be "acceptable", and people are unlikely to be exposed to a toxic level with possible consequences for their health, while if it exceeds 1 there would be a possibility of suffering adverse effects, (Zheng et al., 2007; Evans et al., 2015; Yu et al., 2016).

Assessment of the pdf of $\operatorname{EDI}\left(\mathrm{H}_{\mathrm{i}}\right)$, $\mathrm{HQ}\left(\mathrm{H}_{\mathrm{i}}\right)$ and $\mathrm{HI}$ is more suitable, as not only mean values are obtained for risk characterization but it also captures the effect of uncertainties. It also permits sensitivity and uncertainty analyses to support risk-informed decision-making, as explained in the following section.

\subsubsection{Sensitivity and uncertainty analyses}

The sensitivity and uncertainty analyses (SA and UA) aim to elucidate the dependency of the output, e.g. $\operatorname{EDI}\left(\mathrm{H}_{\mathrm{i}}\right)$, $\mathrm{HQ}\left(\mathrm{H}_{\mathrm{i}}\right)$ and $\mathrm{HI}$ on the set of input parameters in Eqs. (1) to (3). In particular, they are intended to assess how the uncertainty of output depends on the uncertainty of inputs, i.e. to determine the relationship between the variability of the model inputs and 
outputs. There are several SA and UA techniques, such as Sobol decomposition, uncertainty importance measures, parametric and nonparametric regressions, tornado graphs, etc., (Martorell et al., 2014). These analyses provide information regarding the best parameters to most effectively reduce uncertainty in the assessment of the risk metrics of interest, e.g. the HI. The tornado graph is the technique used in the case study described here.

\section{Safety margin of exposure to non- genotoxic chemicals in food}

Safety margins play a central role in coping with the effect of uncertainties in the safety of technological systems. In general, risk-informed regulations establish that adequate margins be maintained between system performance and safety objectives (USNRC, 2016). Within the framework of consumer safety, it is essential to maintain an adequate margin between exposure to non-genotoxic chemicals and the corresponding ADI for the contaminant.

However, there is no universal definition or formulation of the concept of safety margin. For some experts the margin of safety is a synonym for margin of exposure, while for others, margin of safety means the margin between the reference dose and the current exposure (FAO/WHO 2009). Recently, the definition, formulation and use of safety margins were introduced to verify compliance with microbiological safety objectives in food (Domenech \& Martorell, 2016).

In this section, classical and probabilistic metrics are introduced to measure the margin of exposure to nongenotoxic chemical hazards. The formulation of these metrics is inspired by the FSM developed for microbiological hazards (Doménech \& Martorell, 2016).

3.1. Classical formulation of the safety margin

The classical formulation of a food safety margin (c_FSM) for a nongenotoxic chemical hazard, $i$, can be defined in terms of the Euclidean distance between the $\operatorname{EDI}\left(\mathrm{H}_{\mathrm{i}}\right)$ and the $\mathrm{ADI}_{i}$. In Eq. (4), this distance is divided by the $\mathrm{ADI}_{i}$ in order to obtain a value of c_FSM $\left(\mathrm{H}_{\mathrm{i}}\right)$, which always ranges between zero and one. Thus, a value of this metric close to one would indicate a wide margin, i.e. exposure to this nongenotoxic chemical hazard is very unlikely to have consequences for health. On the other hand, a margin close to zero would imply a narrow margin with a high possibility of adverse effects. In Eq. (4) $\mathrm{HQ}\left(\mathrm{H}_{\mathrm{i}}\right)$ is the hazard quotient calculated for each chemical hazard $i$ obtained from Eqs. (1) and (2):

C_FSM $\left(\mathrm{H}_{i}\right)=$
$\left\{\begin{array}{cl}0 & \text { ifHQ }\left(\mathrm{H}_{i}\right)>1 \\ 1-H Q\left(H_{i}\right) & \text { ifHQ }\left(\mathrm{H}_{i}\right) \leq 1\end{array}\right.$

Assessment of c_FSM(Hi) by Eq. (4) is carried out by a standard Monte Carlo method to propagate the variability from the input $\mathrm{HQ}\left(\mathrm{H}_{\mathrm{i}}\right)$ to the output c_FSM $\left(\mathrm{H}_{\mathrm{i}}\right)$, which yields a $p d f$ for c_FSM $\left(\mathrm{H}_{\mathrm{i}}\right)$. The c_FSM $\left(\mathrm{H}_{\mathrm{i}}\right)$ mean and $9 \overline{5}^{\text {th }}$ were also plotted in Fig. 1 for the sake of clarity. As can be observed, the information contained in this metric is extremely valuable because mean values can lead to serious mistakes. As can be seen in Fig 1, the c_FSM $\left(\mathrm{H}_{\mathrm{i}}\right)_{\mathrm{m}}$ for both exposures would be the same, however the complete information that this metric 
provides (e.g. c_FSM $\left(\mathrm{H}_{\mathrm{i}}\right)$ at $5 \%$ or $95 \%$ ), clearly distinguishes between the different safety margins for consumers in each case.

Eq. (4) can be extended to estimate the food safety margin for a mixture of non-genotoxic chemical hazards in food as follows, $\mathrm{Eq}(5)$.

$c_{-} F S M m=\left\{\begin{array}{cc}0 & \text { if } H I>1 \\ 1-H I & \text { if } H I \leq 1\end{array}\right.$

where $\mathrm{HI}$ is the hazard index calculated from Eq. (3).

Uncertainty was assessed by a Monte Carlo method, after which a $p d f$ was obtained for c FSMm.

3.2. Probabilistic formulation of safety margin

The safety margin can be formulated in its probabilistic form (p_FSM) for one non-genotoxic chemical hazard $i$ as follows, Eq. (6):

$$
\begin{aligned}
\operatorname{p\_ } \operatorname{FSM}\left(H_{i}\right)= & \operatorname{Pr}\left\{\mathrm{HQ}\left(\mathrm{H}_{i}\right)<1\right\} \\
& =\int_{0}^{\operatorname{ADI}_{i}} \operatorname{EDI}\left(H_{i}\right) d H \\
& =1 \\
& -\int_{A D I_{i}}^{\infty} \operatorname{EDI}\left(H_{i}\right) d H \\
& =1-E P\left(H_{i}\right)
\end{aligned}
$$

where $\operatorname{EP}\left(\mathrm{H}_{\mathrm{i}}\right)$ is the exceedance probability, which represents the probability that exposure to the nongenotoxic hazard $i$ exceeds the safety limit, herein the $\mathrm{ADI}_{i}$. Fig. 1 shows $\mathrm{EP}\left(\mathrm{H}_{\mathrm{i}}\right)$ in a graphical way (red area). The value obtained with this metric also lies between zero and one.

As occurs in the classical formulation, Eq (6) can be extended in Eq (7) for a mixture of non-genotoxic chemical hazards in food, i.e. p_FSMm:

$p_{-} F S M m=\operatorname{Pr}\left\{\bigcap_{i=1}^{n}\left(H Q\left(H_{i}\right)<1\right)\right\}$

Since the occurrence of events $\left(H Q\left(H_{i}\right)<1\right) \forall i=\{1, n\} \quad$ are independent of each other, then Eq (7) can be simplified to yield:

p_FSMm $=\prod_{i=1}^{n}\left(1-E P\left(H_{i}\right)\right)=$

$\prod_{i=1}^{n} p_{-} F S M\left(H_{i}\right)$

where, $p_{-} F S M\left(H_{i}\right)$ is given by $\mathrm{Eq}(6)$ for each non-genotoxic chemical $i$.

\section{Case Study. Results and discussion}

This section describes the application of the metrics introduced in Sections 2 and 3 to assess the safety margins of consumers' exposure to organophosphorus pesticides in peaches and discusses the results obtained from these metrics.

\subsection{Problem description and data}

Data obtained from the USDA pesticide database in the period 1994 to 2014 were considered (USDA, 2016a). Peaches were chosen because of the considerable amount of available data, ife. a total of 11 years out of 20 in the perjod considered (USDA, 2016a). In addition, the USDA report (2014) contained 38 samples belonging to the group of fruits and vegetables exceeding pesticide tolerance. Peaches were the fruit with the highest number of positives (11 samples) followed by 5 strawberries and 1 banana, 
1 nectarine and 1 sample of watermelon (USDA, 2016a). Similar findings in Europe indicate that peaches had the highest percentage of samples with measurable pesticide residues above the limit of quantification (73\%), followed by $68 \%$ of the apple samples and $68 \%$ of the strawberries (EFSA, 2013). In 2013, $1.1 \%$ of peach samples exceeding the maximum residue limit (MRL) and $53 \%$ of samples had multiple residues, making peaches one of the most contaminated products in that report (EFSA, 2015). Since OPs are extensively used in agriculture, the main route of exposure for the general population is through their diet (EFSA, 2014).

In order to select the most representative pesticides two parameters were considered. Firstly, the mean concentration for each pesticide $i$ and year, $\mathrm{H}_{\mathrm{i}, \mathrm{m}}$, i.e. the mean value of those samples which exceeded the limit of detection (LOD). Secondly, the probability of having a concentration higher than the LOD, $\operatorname{Pr}\left(\mathrm{H}_{\mathrm{i}}>\mathrm{LOD}\right)$, which is calculated as the number of samples per year in which the pesticide $i$ was detected, divided by the total number of samples analysed per year for that pesticide.

Fig. 2 represents the $\operatorname{Pr}\left(\mathrm{H}_{\mathrm{i}}>\mathrm{LOD}\right)$ as the ordinate and $\mathrm{H}_{\mathrm{i}, \mathrm{m}}$ as the abscissa for the 11 years studied. It shows three broad groups surrounded by an ellipse. The first one corresponds to pesticides that had low concentrations and low probabilities. This group includes the majority of the detected pesticides for all the years studied. It shows that, in general, although there are a large number of positives for all the pesticides studied, their concentrations are low. The second group represents pesticides that had a high probability and medium concentrations. The highest values in this group are those of 2001 and 2002 . However, it is notable that no samples from 2013 and 2014 were found. Finally, the third group is formed by pesticides with high concentrations but low probabilities, confirming that high concentrations were only sporadic cases. Moreover, taking into account the year, the highest concentrations were found in 1996, 1995 and 1994, which indicates a general tendency to reduce concentrations over the years.

Fig. 3 plots the results of the product $\operatorname{Pr}\left(\mathrm{H}_{\mathrm{i}}>\mathrm{LOD}\right) * \mathrm{H}_{\mathrm{i}, \mathrm{m}}$ for each pesticide $i$ and year. Higher values can be observed for Azinphos-methyl, Chlorpyrifos and Phosmet, which were present in all the years. Diazinon was also present for the whole period, with the exception of 2013. Parathion-methyl, now prohibited, was found with a high probability from 1994 to 1996, although it was also found in 2000, 2001, 2007 and 2008. Malathion, Methamidophos and Dimethoate were found with different probabilities in seven of the 11 years analysed. The rest of the pesticides (Parathion-ethyl, Mevinphos total, Phosalone, Omethoate, Methidathion, Acephate, Phosmet oxygen analog, Dichlorvos and Fenamiphos sulfoxide) were found in one or two years of the whole period studied and represented less than $0.5 \%$.

Based on the results shown in Figs. 2 and 3, the case study only focuses on pesticides with high average concentrations, a high probability of having a concentration higher than the LOD, or a high combination of both parameters, which is the case of Diazinon, Azinphos-methyl, Parathionmethyl, Chlorpyrifos and Phosmet. 
Table 1 shows the pdf data for the concentrations of each pesticide, $\mathrm{Hi}$, which were obtained from the published database (USDA, 2016a) and fitted using @Risk 5.7 software (Palisade, Middlesex UK). For example, the distribution fitted for Azinphos-methyl in 1994 is $\operatorname{Lognorm}(0.09 ; 0.15$; [0.02; $0.01,7.2]$ ), which means the $p d f$ follows a lognormal distribution in which the first two parameters represent the mean and standard deviation of the distribution. The parameters inside the square bracket represent the distribution shift, minimum and maximum, respectively. In this study, the $p d f$ fitted was truncated to LOD as a realistic minimum value, and was also truncated by up to ten times the highest concentration taken from the database as the maximum possible value.

Table 2 shows the probability of detecting each pesticide, $\operatorname{Pr}\left(\mathrm{H}_{\mathrm{i}}>\mathrm{LOD}\right)$. Table 3 shows consumer body weight information for the period 2007-2010 (CDC, 2012), male/female proportion (UN, 2015) and mean consumption of peaches for the period 2000 to 2014 in the USA (USDA 2016b). In this example, the possible differences between the consumption of peaches by men and women were not considered. Table 4 shows the current ADI for each pesticide, $\mathrm{ADI}_{\mathrm{i}}$, obtained from the Joint FAO/WHO Meeting on Pesticide Residues (JMPR) (WHO, 2012; EU, 2016). Since the aim was not to obtain the safety margin for one year, but to be able to compare and study the evolution of each margin over time as compared to a reference value, the $\mathrm{ADI} \mathrm{I}_{\mathrm{i}}$ used for each pesticide was kept constant at the reference point accepted as the $\mathrm{ADI}_{\mathrm{i}}$ value for 2014 .

\subsection{Assessment of HQ and HI}

The $p d f$ values for $\mathrm{HQ}(\mathrm{Hi})$ and $\mathrm{HI}$ were simulated by Eqs. (1) to (3) in the spreadsheet model with Monte Carlo Latin Hypercube sampling of residue data for the chosen pesticides. After propagation of the pdfs for $\mathrm{EDI}(\mathrm{Hi})$, $\mathrm{HQ}(\mathrm{Hi})$ and $\mathrm{HI}$ the mean, $5^{\text {th }}$ and $95^{\text {th }}$ percentile values for the residues were obtained.

Fig. 4 shows the mean value of the $\mathrm{HQ}\left(\mathrm{H}_{\mathrm{i}}\right)$ contribution of each pesticide to the HI per year and Table 4 the criteria recommended for the classification of organophosphorus pesticides. The results indicate that in this period the $\mathrm{HQ}\left(\mathrm{H}_{\mathrm{i}}\right)$ value of Phosmet (mean and standard deviation: $0.00125 \pm 0.00073$ ) made an important contribution to $\mathrm{HI}$ that also increased with time; i.e. in 1994 it accounted for $37.4 \%$ of the $\mathrm{HI}$ of that year and in 2014 reached the maximum percentage $(94.1 \%$ of $\mathrm{HI})$, which means that almost all the HI was due to Phosmet. Parathion-methyl $\left(\mathrm{HQ}\left(\mathrm{H}_{\mathrm{i}}\right)=0.00028 \pm 0.00048\right)$ was the second most important pesticide in 1994, 1995 and 1996 in terms of its contribution to HI (48, 42.8 and $26.4 \%$, respectively). However, after it was prohibited only one positive sample above the LOD was found (in 2008). Azinphos-methyl

$\left(\mathrm{HQ}\left(\mathrm{H}_{\mathrm{i}}\right)=0.000196 \pm 0.00011\right)$ was more or less constant from 1994 to 2008, with a contribution to HI of $11.8 \pm 3.6 \%$. However, there was a sharp drop in 2013 and 2014, with a contribution to HI of $0.6 \%$ and $0.4 \%$, respectively. Methamidophos was only detected from 2000 to 2008 $\left(\mathrm{HQ}\left(\mathrm{H}_{\mathrm{i}}\right)=0.000062 \pm 0.000068\right)$ with a minimum contribution to $\mathrm{HI}$ of $0.7 \%$ (2008) and a maximum of 7.9\% (2002). Chlorpyrifos 
$\left(\mathrm{HQ}\left(\mathrm{H}_{\mathrm{i}}\right)=0.000063 \pm 0.000035\right)$

increased from 1994 to $2008(0.8-7.1 \%$ of HI) and decreased in 2013 and 2014 (5.7 and 5\%). Diazinon $\left(\mathrm{HQ}\left(\mathrm{H}_{\mathrm{i}}\right)=0.000034 \pm 0.000036\right)$, made the maximum contribution to $\mathrm{HI}$ in 2006 (4\%), after which it fell $(1,0.6,0$ and $0.1 \%$ to $\mathrm{HI})$. Finally, Dimethoate $\left(\mathrm{HQ}\left(\mathrm{H}_{\mathrm{i}}\right)=0.00001 \pm 0.000025\right)$ was either not detected in any samples or made a very small contribution to HI (around $0.5 \%$ ), the only exception being 1995 $(3.3 \%$ of $\mathrm{HI})$.

When these results are compared with those published by other authors the findings vary considerably according to the type of food or group and the pesticides considered. Lemos et al., (2016) concluded that the potential risk, $\mathrm{HQ}$ (pesticides) to consumers through vegetable intake ranges between 0.0010.214 . Jensen et al., (2015) reported that for fruit, vegetables and cereals the HQs for the individual pesticides ranged from 0.0000001 to 0.24 , the values for Phosmet and Azinphos-methyl being 0.0069 and 0.0044 , respectively. These results coincide with the idea that individual chemicals will not generally pose a health risk, but a combination of several chemicals may be an important exception to this (FAO/WHO, 2009).

There was a visible increase in the values of HI from 1994 to 1996, when the maximum mean value was 0.004 . In 2000 , HI was reduced by $42 \%$ in relation to 1996 . From then until 2006 a slight increase can be perceived, with similar values to those obtained in 1994 (mean value $=0.0086$ ). Finally, after 2007 a continuous decrease in HI was seen, with a minimum value in 2013 (mean value $=0.0002$ ). Comparing these results with those of other authors, there are differences that depend on the scope of the different studies. Jensen et al., (2015) found that for fruit, vegetables and cereals HI ranges from 0.018 for adults to 0.44 for children. However, when more than $550 \mathrm{~g}$ of fruit and vegetables were eaten in a day, the HI increased by a factor of 2 for men ( 0.14 to 0.29$)$ and 1.7 for women (0.20-0.33). Higher values were found by $\mathrm{Yu}$ et al., (2016), who concluded that the HI due to 11 pesticides in fresh vegetables in Changchun (China) was 0.448 for adults and 0.343 for children, while low values of HI from $5.5^{*} 10^{-6}$ to 0.002 were found in honey samples (Juan-Borrás et al., 2016).

4.3. Assessment of classical and probabilistic safety margins

The $p d f$ of c_FSMm and p_FSMm was estimated by Monte Carlo simulation using Eqns. (4) to (8) and Latin Hypercube sampling.

Fig. 5 shows the mean, $5^{\text {th }}$ and $95^{\text {th }}$ percentile for the classical FSM of exposure to a mixture of OPs in peaches corresponding to the $p d f$ of c_FSMm. In general, an increase in the mean of the c_FSMm margin can be observed from 2006 (0.99778) to 2014 (0.99955). The range of variability given by the distance between the $5^{\text {th }}$ and $95^{\text {th }}$ percentiles indicate a reduction of the uncertainty in the safety margin for the last two years simulated, the minimum uncertainty range occurring in 2013, followed by 2014. The findings also show that the worst mean and the greatest uncertainty of the safety margin is in 1996, followed by 1995 .

A sensitivity analysis was performed to study the effects of the variation of input parameters on the final output, c FSMm. The parameters with the 
highest relative effects are considered the most sensitive input parameters. The tornado diagram in Fig. 6 shows that in this application the most sensitive input is the probability that samples have a higher concentration of Phosmet than the LOD. Similarly, the second most sensitive input parameter is the Phosmet concentration. The rest of the parameters such as consumption, probability of positive samples of Chlorpyrifos and the sex of the consumer, which is directly related to body weight, have less influence on the margin. Finally, the concentrations of Chlorpyrifos, Azinphos-methyl and Dimethoate are in the lower part of the tornado.

Overall, large classical safety margins were observed close to one with small uncertainty in the period studied It is also shown that not only were the mean values of classical safety margins increased in the later years, but also that uncertainty was reduced, which may be associated with better risk management practices (Marvin et al., 2009).

The result obtained for $\mathrm{p}_{-} \mathrm{FSMm}$ is one in all the years studied, with the exception of 1996 (0.999985). This means there is only a non-zero exceedance probability, EP(Hi), in 1996, with a very low probability $(0.000015)$ of exceeding the safety limit established, i.e. the ADI. This means that OP exposure remains below the ADI for the remaining years. This result is consistent with the very high values found for the $5^{\text {th }}$ percentile of the classical c_FSMm for the same years.

Although both metrics provide a similar conclusion, the probabilistic approach gives additional information. The probabilistic safety margin indicates the probability of the exposure exceeding the threshold and what this implies in terms of risk. Let us take 1996 as an example; the classical safety margin c_FSMm is very high and close to one. The probabilistic safety margin p_FSMm indicates that, even so, there is no null probability of exposure exceeding the ADI as a consequence of uncertainties, although the probability is very small in this case, i.e. the exceedance probability is around $(0.000015)$.

The information provided by the probabilistic safety margin in this particular application is very limited, since the safety margin is one for almost all the years. The probabilistic approach would provide better information when EDIs are close to the corresponding ADIs and the $p d f$ of the EDIs has negative kurtosis.

\section{Concluding remarks}

Incorrect agricultural practices and improper use of chemicals during processing have contributed to the introduction of hazards in the food chain. In the framework of hazard characterization, in particular for nongenotoxic hazards, HQ and HI risk metrics have been used to predict and manage human exposure to multiple chemicals and their associated toxicological effects. However, these metrics do not take into account the effect of variability and the uncertainties of the many factors affecting the quantification of HQ and HI. In this regard, the Codex emphasises that the evaluation of uncertainties in risk assessment is a crucial issue (CAC, 2013).

This paper introduces the concept and formulation of FSM as an alternative approach to hazard characterization. 
FSM is based on the fundamentals of the definition of HQ and HI, but also allows for the effect of variability and uncertainty. Two complementary FSM metrics are proposed, i.e. classical and probabilistic FSM, as tools for verifying compliance with safety goals in relation to exposure to non-genotoxic chemical hazards in food. The classical approach c_FSM $\left(\mathrm{H}_{\mathrm{i}}\right)$ is more appropriate when exposure to non-genotoxic chemical hazards is well below the safety limit $\left(\mathrm{EDI}\left(\mathrm{H}_{\mathrm{i}}\right)<<\mathrm{ADI}_{\mathrm{i}}\right)$. The probabilistic approach, $p \operatorname{FSM}\left(\mathrm{H}_{\mathrm{i}}\right)$, is appropriate in all cases, since it provides additional information on the effects of variability and uncertainty, which are responsible for situations in which the $\operatorname{EDI}\left(\mathrm{H}_{\mathrm{i}}\right)$ exceeds the ADI. These situations will most likely occur when exposure is close to the safety limits (EDI close to ADI) but they may also occur in situations where exposure is below the safety limits, as was found in the 1996 case study, according to the kurtosis of the $p d f$ for the EDI.

The results of the case study show large classical and probabilistic safety margins and indicate that OP pesticides in peaches are not a principal pathway for dietary exposure in humans.

It can therefore be concluded that, in spite of having considered the most significant pesticides, the assessment of safety margins of individual foods, e.g. peaches, is inappropriate and that the entire diet should be considered. Future research should include the complete characterization of the risk of exposure to non-genotoxic chemicals in the human diet and the possible synergic effects.

\section{References}

AECOSAN (2014). Memoria AECOSAN Agencia Española de Consumo, Seguridad Alimentaria y Nutrición http://aesan.msssi.gob.es/AESAN/docs/d ocs/publicaciones_estudios/memoria/Me moria__AECOSAN_2014.pdf (AccessedDecember 2016).

Boobis, A.R., Ossendorp, B.C., Banasiak, U., Hamey, P.Y., Sebestyen, I., \&Moretto, A.(2008). Cumulative risk assessment of pesticide residues in food. Toxicol. Lett. $180,137-150$

CAC. (2007). Principles and guidelines for the conduct of microbiological risk management. Codex Alimentarius Commission CAC/GL 63-2007. http://www.codexalimentarius.org /standards/list-of-standards/es/?provide= standards\&orderField

$=$ fullReference \&sort $=$ asc\&num $1=\mathrm{CAC} /$ GL (Accessed December 2016).

CAC. (2013). Working principles for risk analysis for application in the framework of Codex Alimentarius. In: Procedural manual, 21st edition. Rome: Food and Agriculture Organization of the United Nations and World Health Organization, Joint FAO/WHO Food Standards Programme, Codex Alimentarius Commission; 107-13 http://www.fao.org/3/a-i3243e.pdf (Accessed December 2016).

CDC.(2012). Anthropometric Reference Data for Children and Adults: United States, 2007-2010. Vital and health statistics. Series 11, U.S. Department of Health and Human Services Centers for Disease Control and Prevention National Center for Health Statistics http://www.cdc.gov/nchs/data/series/sr_1 1/sr11_252.pdf(Accessed December 2016).

Doménech, E. Escriche, I., \&Martorell, S. (2007). Quantification of risks to consumers' health and to company'sincomes due to failures in food safety. Food Control18, 1419-1427.

Doménech, E. \&Martorell, S.(2016). Definition and usage of food safety margins for verifying compliance of Food Safety Objectives. Food Control, 59, 669-674. 
Dorne, J.L.C.M.,\& Fink-Gremmels, J. (2013). Human and animal health risk assessments of chemicals in the food chain:Comparative aspects and future perspectives. Toxicology and Applied Pharmacology 270, 187-195.

EFSA. (2011). Overview of the procedures currently used at EFSA for the assessment of dietary exposure to different chemical substances. European Food Safety Authority. EFSA Journal 2011;9(12):2490.

http://www.efsa.europa.eu/sites/default/fi les/scientific_output/files/

main_documents/2490.pdf (Accessed December 2016)

EFSA.(2013). The 2010 European Union Report on Pesticide Residues in Food. European Food Safety Authority. EFSA Journal 2013;11(3):3130.

http://www.efsa.europa.eu/en/efsajournal /pub/3130 (Accessed December 2016).

EFSA. (2014). Harmonisation of human and ecological risk assessment of combined exposure to multiple chemicals. European Food Safety Authority https:/www.efsa.europa.eu/ sites/default/files/assets/140911briefingn otes.pdf. (Accessed January 2017).

EFSA.(2015). The 2013 European Union report on pesticide residues in food. European Food Safety Authority. EFSA Journal 2015;13(3):4038.

https:/www.efsa.europa.eu/en/efsajourna 1/pub/4038 (Accessed December 2016).

EPA, 1986. Guidelines for the Health Risk Assessment of Chemical Mixtures. U.S. Environmental Protection Agency.https://www.epa.gov/risk/guideli nes-health-risk-assessment-chemicalmixtures (Accessed January 2017).

Evans, R.M., Scholze, M., \&Kortenkamp A. (2015). Examining the feasibility of mixture risk assessment: A case study using a tiered approach with data of 67 pesticides from the Joint FAO/WHO Meeting on Pesticide Residues (JMPR). Food. Chem. Toxicol. 84, 260-269.

EU (European Union). (2016). Pesticides database European Commission. http://ec.europa.eu/food/plant/pesticides/ eu-pesticides-database

(Accessed

December 2016).

FAO/WHO.(2005). Food safety risk analysis an overview and framework manual. https://www.fsc.go.jp/sonota/foodsafety riskanalysis.pdf (Accessed December 2016).

FAO/WHO. (2006). The use of microbiological risk assessment outputs to develop practical risk management strategies: metrics to improve food safety.ftp://ftp.fao.org/ag/agn/food/kiel.p df. (Accessed January 2017).

FAO/WHO. (2009). Principles and methods for the risk assessment of chemicals in food International Programme on Chemical Safety

(IPCS), http://www.who.int/foodsafety/publicatio ns/chemical-food/en/ (Accessed December 2016).

IPCS (2008) Uncertainty and data quality in exposure assessment. Part 1: Guidance document on characterizing and communicating uncertainty in exposure assessment. Part 2: Hallmarks of data quality in chemical exposure assessment. Geneva, World Health Organization, International Programme on Chemical Safety

http://www.who.int/ipcs/publications/me thods/harmonization/ (Accessed January 2017).

Jensen, B.H., Petersen, A., Nielsen, E., Christensen, T., Poulsen, M.E., \&Andersen, J.H.(2015). Cumulative dietary exposure of the population of Denmark to pesticides.Food and Chemical Toxicology, 83, 300-307.

Juan-Borrás, M., Domenech, E.,\&Escriche, I. (2016). Mixture-risk-assessment of pesticide residues in retail polyfloral honey. Food Control, 67, 127-134.

Kortenkamp, A., Backhaus, T., \&Faust, M. (2009). State of the Art on Mixture Toxicity.

http://ec.europa.eu/environment/chemica ls/effects/pdf/report_mixture_toxicity.pdf (Accessed December 2016).

Leeuwen C.J. \&Vermeire T.G. (2007). Risk Assessment of Chemicals: An Introduction. Published by Springer, P.O. 
Box 17, 3300 AA Dordrecht, The Netherlands.

http://www.acad.bg/ebook/cheminformat ics/van\%20Leeuwen_Risk\%20Assessme nt $\% 20$ of $\% 20$ Chemicals-

An\%20Introduction\%202nd\%20ed.pdf

(Accessed January 2017).

Lemos, J., Sampedro, M.C., Ariño, A., Ortiz, A., \& Barrio, R.J. (2016). Risk assessment of exposure to pesticides through dietary intake of vegetables typical of the Mediterranean diet in the Basque Country. Journal of Food Composition and Analysis, 49, 35-41.

Martorell, S.,Villamizar, M.,Martón, I., Villanueva, J.F.,.Carlos, S.,\&Sánchez, A.I. (2014). Evaluation of risk impact of changes to surveillance requirements addressing model and parameter uncertainties. Reliability Engineering \& System Safety,126, 153-165.

Marvin, H.J.P., Kleter, G.A., Frewer, L.J., Cope, S.,Wentholt, M.T.A., \&Rowe. G. (2009). A working procedure for identifying emerging food safety issues at an early stage: Implications for European and international risk management practices. Food control 20, 345-356.

UN (United Nations). (2015). Population Pyramids of the World. United Nations, Department of Economic and Social Affairs, Population Division. World Population Prospects: The 2015 Revision https:/populationpyramid.net/es/estadosunidos/2015/ (Accessed December 2016).

USDA.(2016a). Pesticide Data Program-Annual Summary, Calendar Year 2014 https://www.ams.usda.gov/sites/default/fi les/media/2014\%20PDP\%20Annual\%20 Summary.pdf(Accessed December 2016).

USDA.(2016b). Per capita consumption of fresh peaches and nectarines in the United States from 2000 to 2014. US Department of Agriculture; Economic Research Service https://www.statista.com/statistics/25722 9/per-capita-consumption-of-freshpeaches-and-nectarines-in-the-us/ (Accessed December 2016).

USNRC 2016 Risk-informed regulation. United States nuclear regulatory commission. https://www.nrc.gov/aboutnrc/regulatory/risk-

informed/concept.html

(Accessed

January 2017)

WHO. (2004). IPCS (International Programme on Chemical Safety) risk assessment terminology. Part 1: IPCS/OECD key generic terms used in chemical hazard/risk assessment. Part 2: IPCS glossary of key exposure assessment terminology. Geneva, World Health Organization, International Programme on Chemical Safety (Harmonization Project Document No. 1; http://www.inchem.org/documents/harm proj/harmproj/harmproj1.pdf (Assessed December 2016).

WHO. (2010). The WHO Recommended Classification of Pesticides by Hazard and Guidelines to Classification 2009. WHO Library Cataloguing-in-Publication Data. http://www.who.int/ipcs/publications/pes ticides_hazard_2009.pdf (Accessed December 2016).

WHO. (2014). Guidance document on evaluating and expressing uncertainty in hazard characterization. IPCS project on the Harmonization of Approaches to the Assessment of Risk from Exposure to Chemicals.

http://www.inchem.org/documents/harm proj/harmproj/harmproj11.pdf. (Accessed January 2017).

WHO, (2012). Joint FAO/WHO Meeting on Pesticide Residues (JMPR) http://apps.who.int/pesticide-residuesjmpr-database(Accessed February 2017)

Yu, R., Liu, Q., Liu, J., Wang, Q., \&Wang, Y. (2016). Concentrations of organophosphorus pesticides in fresh vegetables and related human health risk assessment in Changchun, Northeast China. Food Control 60, 353-360.

Zheng, N., Wang, Q., Zhang, X., Zheng, D., Zhang, Z., \&Zhang, S. (2007). Population health risk due to dietary intake of heavy metals in the industrial area of Huludao city, China. Sci.Total Environ. 387, 96104. 


\section{Figure captions}

Fig. 1. Relationship between the concepts of exposure daily intake, $\operatorname{EDI}\left(\mathrm{H}_{\mathrm{i}}\right)$, admissible daily intake, $\mathrm{ADI}$, classical safety margins, c_FSM $\left(\mathrm{H}_{\mathrm{i}}\right)$, and exceedance probability, $\mathrm{EP}\left(\mathrm{H}_{\mathrm{i}}\right)$, for two examples of exposure to a non-genotoxic chemical hazard, i. Mean value and $5^{\text {th }}$ and $95^{\text {th }}$ percentiles are represented.

Fig. 2. Relationship between the probability of resulting an OPs concentration higher than the level of detection, $\operatorname{Pr}\left(\mathrm{H}_{\mathrm{i}}>\mathrm{LOD}\right)$, and the mean concentration, $\mathrm{H}_{\mathrm{i}, \mathrm{m}}$, for pesticide iand year.

Fig. 3. Plot of the product between probability of resulting an OPs mean concentration higher than the level of detection per the mean concentration $\left[\operatorname{Pr}\left(\mathrm{H}_{\mathrm{i}}>\mathrm{LOD}\right)^{*} \mathrm{H}_{\mathrm{i}, \mathrm{m}}\right]$ for each pesticide and year studied.

Fig. 4. $\mathrm{HQ}\left(\mathrm{H}_{i}\right)$ contribution to mean $\mathrm{HI}$ per OPs in peaches and year.

Fig. 5. Evolution of the classic safety margin of a mixture of OPs in peaches (c_FSMm)per year. Mean, $5^{\text {th }}$ and $95^{\text {th }}$ percentiles.

Fig. 6. Sensitivity analysis of the classic safety margin of a mixture of OPs in peaches c_FSMm corresponding to year 2014. 